\title{
Evaluation of pore system from outcrop rocks by mercury intrusion porosimetry
}

Lorena Alves Bahia Figueiredo*, Roseane Misságia, Marco Ceia, Nathaly Archilha, Irineu Lima Neto. UENF/LENEP

Copyright 2014, SBGf - Sociedade Brasileira de Geofísica

Este texto foi preparado para a apresentação no VI Simpósio Brasileiro de Geofísica, Porto Alegre, 14 a 16 de outubro de 2014. Seu conteúdo foi revisado pelo Comitê Técnico do VI SimBGf, mas não necessariamente representa a opinião da SBGf ou de seus associados. É proibida a reprodução total ou parcial deste material para propósitos comerciais sem prévia autorização da SBGf.

\section{Summary}

The article describes some characteristics of the Sandstones and Carbonates outcrop rocks. Carbonates rocks present a complex pore system with a broad pore size range, thus requiring special techniques to characterize such heterogeneous porous sandstone however, typically have a more regular pore size and distribution, and this way a more homogeneous pore system when compared to carbonates. The main goal at this work is to use the mercury porosimetry technique to identify the pore system of samples of these types of rocks, and estimate the permeability $(k)$ by KozenyCarmen correlation of using gas porosity $(\phi)$ and tortuosity $(\tau)$, which was determined by resistivity.

\section{Introduction}

The technique mercury porosimetry is a well-known used for porous materials characterization where the pores can be investigated between $500 \mu \mathrm{m}$ and $3.5 \mathrm{~nm}$. Furthermore, this technique provides other important information, such as, the specific surface area, pore size distribution, porosity, hysteresis (Giesche, 2006). This way, mercury porosimetry is an important method for evaluation of the pore structure for a wide variety of porous material.

Mercury behaves as a non-wetting liquid towards most substances and consequently it does not penetrate spontaneously into the smaller pores, but requires a certain pressure to penetrate into the smallest pores.

In this article mercury porosimetry will be applied in 5 outcrop rock samples from US basins (Tab. 1), to find pore size distribution, hysteresis, saturation and permeability was estimated in 5 samples according to Kozeny - Carman theory and these results compared with gas permeability.

\section{Theory and Method}

The Washburn equation is the basic calculation in mercury porosimetry and clearly provides a simple and convenient relationship between applied pressure and pore size (Léon, 1998).

$\Delta \mathrm{P}=\gamma\left(\frac{1}{\mathrm{r}_{1}}+\frac{1}{\mathrm{r}_{2}}\right)=\frac{2 \gamma \cos \theta}{\mathrm{r}_{\text {pore }}}$,

where $r$ is the surface tension of mercury, $r_{1}$ and $r_{2}$ describe the curvature of that interface, $r_{\text {pore }}$ the corresponding pore throat size and $\theta$ the contact angle between the solid and mercury. Generally the pore shape is quite different to the cylinder pore assumption; which can lead to major differences between the analysis and reality.

Accordingly Giesche, (2006), contact angle for non wetting liquids like mercury for which $90^{\circ}<\theta<180^{\circ}$.

Contact angle for non - wetting liquids like mercury as indicated in Eq. 1 that provides a relationship between pressures and pore size. The initial pressure is necessary to penetrate the mercury to the cell, for upper pressure limit applied by equipments in the porous material is 60,000 psi.

Table 1 - Shows the porosity (mercury and gas) of the rocks used in this work.

\begin{tabular}{|c|c|c|c|}
\hline \multicolumn{2}{|c|}{ Sample } & Porosity (Mercury) \% & Porosity (Gas) \\
\hline \multirow{3}{*}{ Sandstones } & Idaho Gray & 8.54 & 30.18 \\
\cline { 2 - 4 } & Nugget & 8.45 & 10.20 \\
\hline \multirow{3}{*}{ Carbonates } & Desert Pink & 17.05 & 26.83 \\
\cline { 2 - 4 } & Edwards Yellow & 28.64 & 22.10 \\
\cline { 2 - 4 } & Wisconsin & 5.06 & 4.08 \\
\hline
\end{tabular}

Observe in Tab. 1 some samples showed mercuryporosity higher than gas porosity, this situation can be explicated because the mercury porosimetry analysis used small cuttings while the other analysis used ( 3 " $L x$ 1.5 "D) core samples.

Pore Size and Pressure

The pore size distribution is determined by mercury intrusion into pores as function of the applied pressure using Eq.1 (Léon, 1998). The volume of mercury penetration for each pressure is the difference between the respective cumulative intrusion volumes (Webb, 2001), as pressure increase, mercury is penetrated into the small pore throat.

There are many classifications for pore size system, mercury porosimetry determines pore size throat not the pore size (Giesche, 2006). According to Winland, (apud Pittman, 1992), the best correlation between fluid flow through the rock and pore throat size is when $35 \%$ of the pore space is saturated by mercury (Tab. 2). Larger pore throats are filled at a low pressure while the smaller can be filled only at high pressure. 
Table 2 - Classification of the pore throat size.

\begin{tabular}{|c|c|}
\hline Classification & Pore Throat size (r35), $\mu$ \\
\hline Mega & $>10$ \\
\hline Macro & $2-10$ \\
\hline Meso & $0.5-2$ \\
\hline Micro & $0.1-0.5$ \\
\hline Nano & $<0.1$ \\
\hline
\end{tabular}

Hysteresis

The porosimetry mercury hysteresis test occurs between the intrude (Increasing Pressure) and extrude process (Decreasing pressure). Pores rarely are of uniform shape, the throat or entrance opening to a pore is smaller than the actual cavity. During the extrusion process new mercury interfaces have to be created as the mercury retracts from the pore system. If the pores were uniform, the intrusion and extrusion happen at the same pressure, but generally samples show varied of geometries (Giesche, 2006).

\section{Resistivity, Formation Factor, Frequency and Tortuosity}

Electrical resistivity is the measure of the material ability to resist to the electric current. In 1942, Archie experimentally that the resistivity of a rock completely saturated with a conductive fluid, $R_{0}$, is related to the resistivity of the conductive fluid, $\mathrm{R}_{\mathrm{W}}$ (Eq. 2).

$\mathrm{R}_{0=} \mathrm{FRF} * \mathrm{R}_{\mathrm{w}}$

where FRF is the formation resistivity factor. When Archie plotted FRF vs. rock porosity $(\phi)$, he found (Eq. 3).

$$
\mathrm{FRF}=\phi^{-\mathrm{m}},
$$

the exponent " $\mathrm{m}$ " represents the slope of the linear trend of FRF vs. $\phi$ when plotted on logarithmic scales. Archie stated that $\mathrm{m}$ will vary according to the degree of cementation of the rock (Borai, 1987).

The frequency range that can be used depends in part on the electrode material and geometry.

The frequency range that can be used depends in part on the electrode material and geometry. With a two-electrode system, the lowest frequency that should be applied will depend on the electrode impedance, which can be considered as a parallel circuit in series with the sample.

The low phase-angle requirement in two-electrode systems usually means operating at frequencies of 100 $\mathrm{Hz}$ or above, but this limiting value varies with the rock mineralogy and electrode type (Worthington, 1975).

Moreover, tortuosity $(\tau)$ is another important parameter because it defines the way that the fluid flow inside the rock.

Tortuosity has been theoretically defined as the ratio of the mean path length to the straight line of porous medium length. It varies according to the geometry of the pores, porosity, FRF, and pressure, cementation factor (Atlia, 2005). In laboratory tests the correlation of tortuosity is the product of porosity and FRF as shown in Eq. 4 (Latour, 1995).

$\mathrm{F} * \phi=\tau$

Azar et al., (2008), suggested another correlation for determine the tortuosity (Eq. 5).

$$
(\mathrm{F} * \phi)^{\mathrm{X}}=\tau
$$

Here $x$ is a correlation constant that varies between 0.5 and 1.5. In this article, was utilized $x$ equal 1.0.

\section{Specific Surface Area}

Specific surface area per unit pore volume is the internal surface area per volume, where the surface area $A_{s}$ for $\mathrm{n}$ capillary tubes is $\mathrm{n}(2 \pi \mathrm{rL})$ and the pore volume is $n\left(\pi r^{2} L\right)$ (Eq.6).

$S_{V p}=\frac{A_{s}}{V_{P}}=\frac{n(2 \pi r L)}{n\left(\pi r^{2} L\right)}=\frac{2}{r}$

$\mathrm{S}_{\mathrm{vgr}}$ is the specific surface area of a porous material or the total area exposed within the per space per unit of grain volume. For a bundle of capillary tubes, the total area exposed, $A_{t}$, is equivalent to the internal surface area $A_{S}$; the grain volume, $\mathrm{V}_{\mathrm{gr}}$, is equal to $\mathrm{A}_{\mathrm{c}} \mathrm{L}(1-\phi)$ ( Eq. 7). Where $A_{c}$ the total cross- sectional area and $\mathrm{L}$ is Length (Tiab \& Donaldson, 2011).

$\mathrm{S}_{\mathrm{vgr}}=\frac{\mathrm{n}(2 \pi \mathrm{rL})}{\mathrm{A}_{\mathrm{c}} \mathrm{L}(1-\phi)}=\frac{2 \pi n r}{\mathrm{~A}_{\mathrm{c}}(1-\phi)}=\frac{\pi \mathrm{r}^{2}}{\mathrm{~A}_{\mathrm{c}}}\left(\frac{2}{\mathrm{r}}\right) \frac{1}{(1-\phi)}$,

combining Equations 6 and 7 gives:

$\mathrm{S}_{\mathrm{vgr}}=\mathrm{S}_{\mathrm{Vp}}\left(\frac{\phi}{1-\phi}\right)$

Note that was considered a porous system of capillary bundles, because the Washburn equation use the same consideration.

\section{Permeability}

Permeability is the ability of a rock to permit fluids to flow through the interconnected pores. Carbonates have a complex and heterogeneous pore system, which makes it difficult to estimate the permeability. One of the correlations to estimate permeability in rocks is the Kozeny-Carman (Carman, 1937), which correlates permeability to porosity, tortuosity and specific surface area per unit grain volume $\left(\mathrm{S}_{\mathrm{vgr}}\right)$. Important properties that directly interfere with the fluid flow in the rock (Izadi, 
2012). Whereas the circular pore in Eq. 9, which was used in this work to estimate permeability.

$\mathrm{k}=\frac{\phi^{3}}{(1-\phi)^{2}}\left[\frac{1}{2 \tau^{2} \mathrm{~S}_{\mathrm{gv}}^{2}}\right]$

To get more specific estimations of permeability(Tab.3), the values $\tau$ and $S_{\text {vgr }}$ were analyzed using all pore throat radius of each rock, then the sum of $\tau$ and $S_{\mathrm{vgr}}$.

Table 3 - Gas and estimated permeability.

\begin{tabular}{|c|c|c|c|c|}
\hline \multicolumn{2}{|c|}{ Sample } & $\begin{array}{c}\text { Gas } \\
\text { Permeability } \\
(\mathrm{mD})\end{array}$ & $\begin{array}{c}\text { Estimated } \\
\text { permeability } \\
(\mathrm{mD}) \text { - selecting } \\
\text { pore size }\end{array}$ & $\begin{array}{c}\text { Estimated } \\
\text { Permeability } \\
(\mathrm{mD}) \text { - all pore } \\
\text { size }\end{array}$ \\
\hline \multirow{4}{*}{ Sandstones } & Idaho Gray & 3332.15 & 3162.87 & 2.91 \\
\cline { 2 - 5 } Carbonates & Nugget & 5.90 & 6.32 & 0.07 \\
\hline & $\begin{array}{c}\text { Edwards } \\
\text { Yellow }\end{array}$ & 32.78 & 31.60 & 0.28 \\
\cline { 2 - 6 } & Wisconsin & 0.004 & 0.06 & 0.03 \\
\hline
\end{tabular}

Results

Fig. 1 shows a graph of cumulative intruded volume information in relation to the increased pressure up to 60 , $000 \mathrm{psi}$. This behavior is easily correlated to porosity (mercury) found in each sample, as shown in Tab. 1. Edwards Yellow showed the highest porosity was, and consequently the greater penetrated volume.

In Fig. 2, it is observe that initially the saturation curve at low pressures behaves like a vertical line, because the pressure was not enough to penetrate the pore throat. When the pressure increases, the pores throat begins to be penetrated, according to Eq.1. It is observe that at lowpressure larger pores are filled, for example, Edwards Yellow which has larger pores and a saturation curve starting at low pressures.

Fig. 3 emphasizes the hysteresis of individual sample, allows to observe the behavior of carbonates (Edwards Yellow and Desert Pink). Such behavior is different from sandstone (Idaho Gray and Nugget). The extruded process due to heterogeneity of the porous system of carbonates process is showing a decrease in volume at low pressure, while for sandstones the extrusion curve remains nearly constant.

Fig. $4-8$ shows the pore size highlighted contributed for estimate the permeability (Eq. 9) using selected porous. Sandstones (Fig .4 - 5) - Idaho Gray (Pore Throat Ratios> $1.86 \mu \mathrm{m}$ ), and Nugget (Pore Throat Ratios> $0.3 \mu \mathrm{m}$ ) and carbonates (Fig. 6 - 8) - Edwards Yellow (Pore Throat Ratios> $1.66 \mu \mathrm{m}$ ), Desert Pink (Pore Throat Ratios> 1.14 $\mu \mathrm{m})$, Wisconsin (Pore Throat Ratios> $0.024 \mu \mathrm{m}$ ).

Fig. 9 shows the permeability behavior when the estimate was performed with all porous sizes and selected porous sizes (Tab.3). The results of these estimates were compared with measurements of permeability to gas. In this work the pore throat radius was qualified according to Winland, (apud Pittman, 1992). Edwards Yellow and Desert Pink present highest values porosity, explaining why the saturation curve starts at low pressure. On another way Nugget started at higher pressure and exhibit smaller pore throat size.

The frequency of each rock used to calculate the resistivity showed the lowest phase angle.

\section{Conclusion}

This work intended to find pore size distribution, hysteresis, saturation and permeability (k) in outcrop rocks by mercury porosimetry, that are principally useful in comparative studies of similar material. Follow are the results of this work:

- Although the equipment was limited to 60,000 psi, the experiments were successful to fill out even the smallest pores; henceforth it was possible to evaluate pore size distribution for each of the samples.

- Through the observation of hysteresis behavior, it was possible to note that the samples, which have larger pore sizes, exhibited a decrease in the mercury volume during extrusion while the ones containing smaller pores showed a constant value.

- The saturation curve is linked to the dispersion in pore throat size distribution. For rocks showing little dispersion, this curve is straight, while for a wider dispersion, the curve is inclined.

- To estimate the permeability using Eq. 9 is required to analyze the porous system because some pores of the rock don't contribute to a close estimate the permeability gas. 


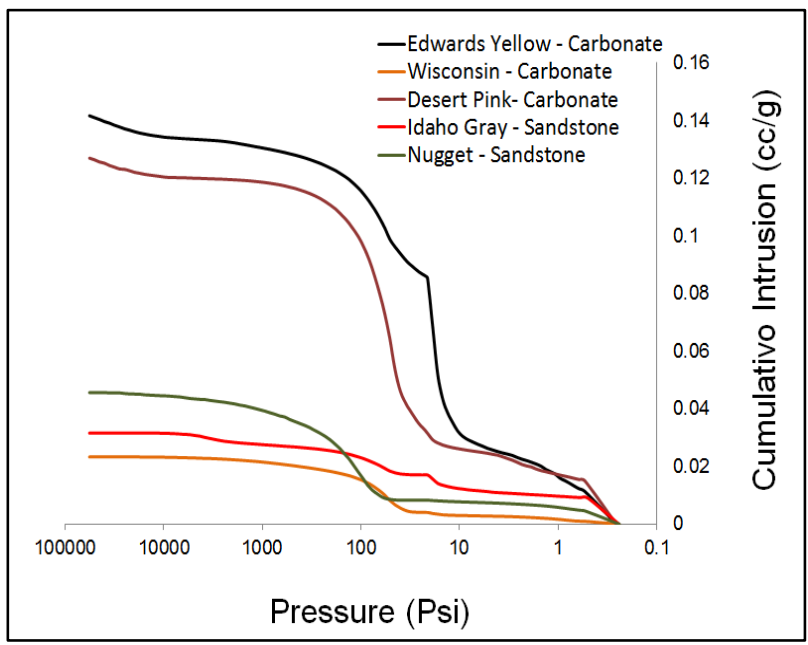

Figure 1- Pressure curve show increase cumulative intrusion until the maximal $\mathrm{Hg}$ pressure for sandstone and carbonate rocks.

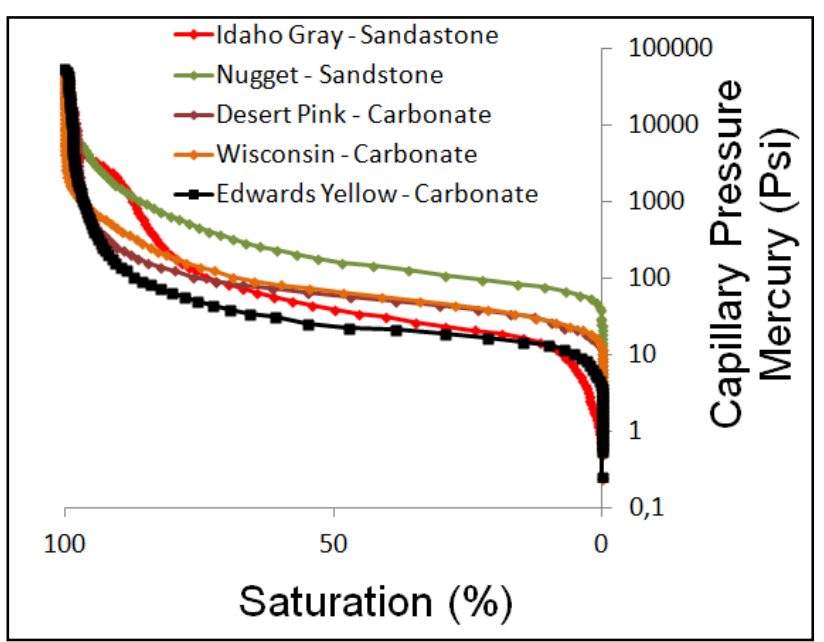

Figure 2 - Mercury saturation (\%) versus Mercury Capillary Pressure (psi) using mercury porosimetry for sandstone and carbonate rocks.

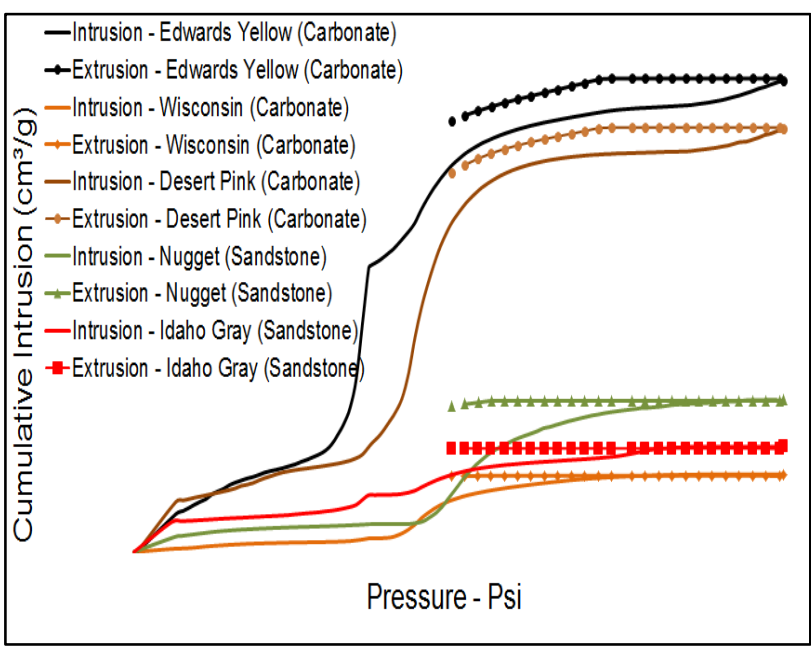

Figure 3 - Mercury porosimetry Hysteresis, pressure (psi) versus cumulative intrusion $\left(\mathrm{cc}^{3} / \mathrm{g}\right)$ for sandstone and carbonate rocks.

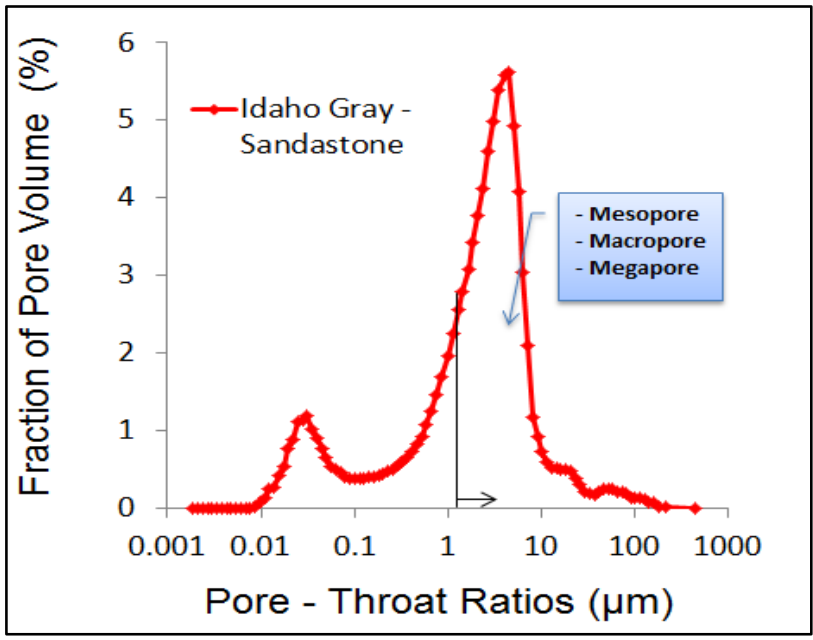

Figure 4 - Identification of pore sizes that contributed to estimate the permeability - Idaho Gray. 


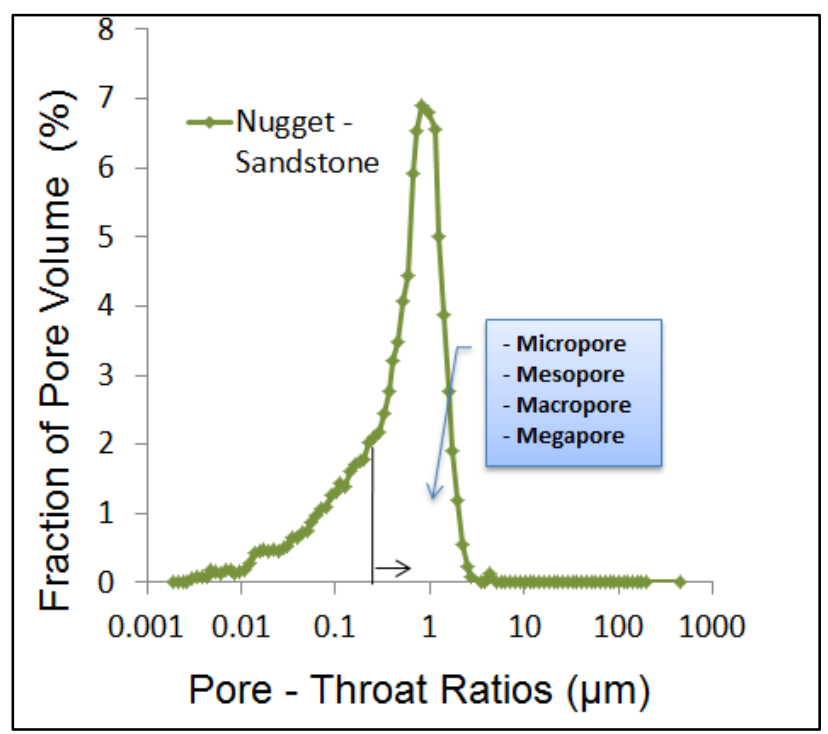

Figure 5 - Identification of pore sizes that contributed to estimate the permeability - Nugget.

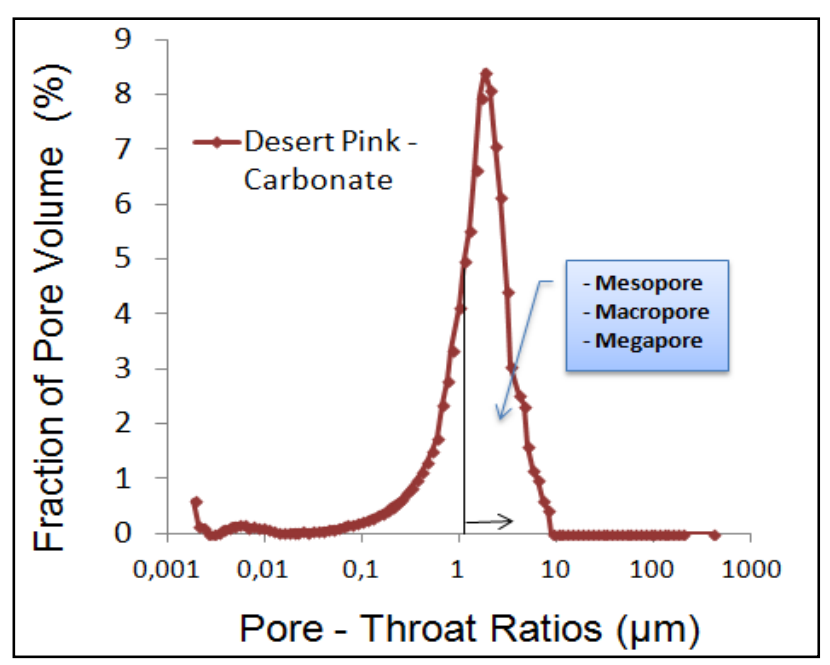

Figure 6 - Identification of pore sizes that contributed to estimate the permeability - Desert Pink.

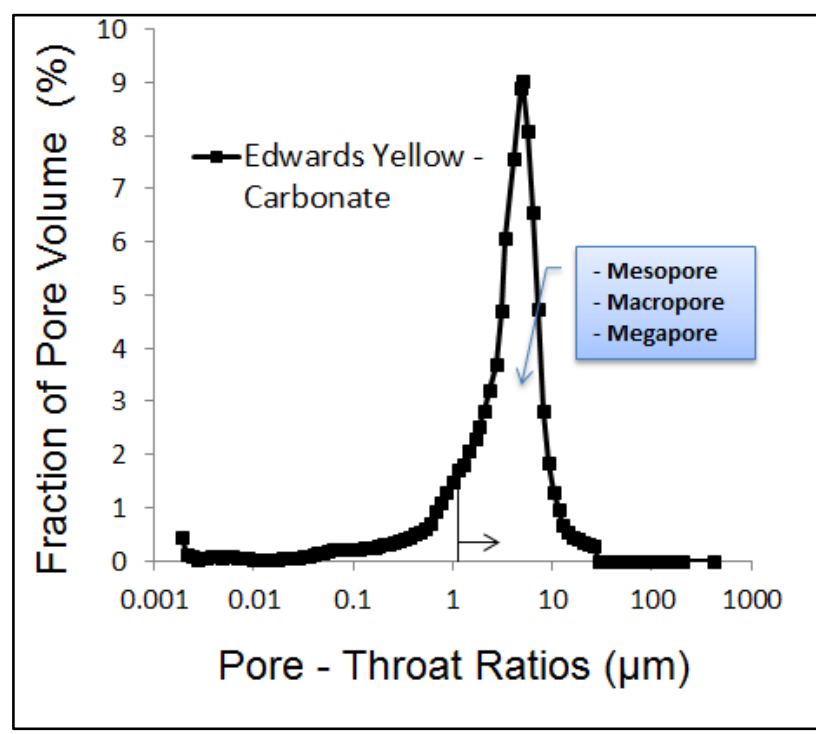

Figure 7 - Identification of pore sizes that contributed to estimate the permeability - Edwards Yellow.

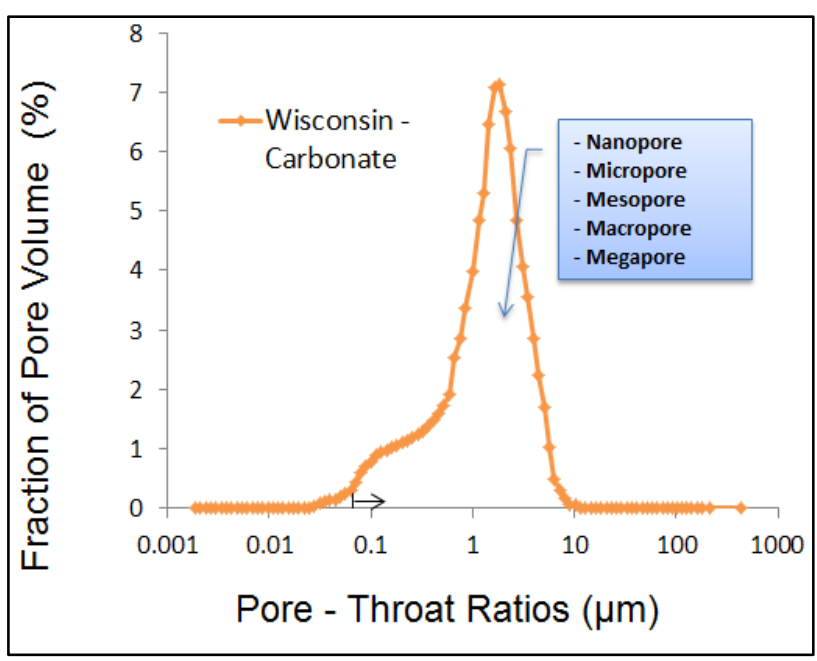

Figure 8 - Identification of pore sizes that contributed to estimate the permeability - Wisconsin.

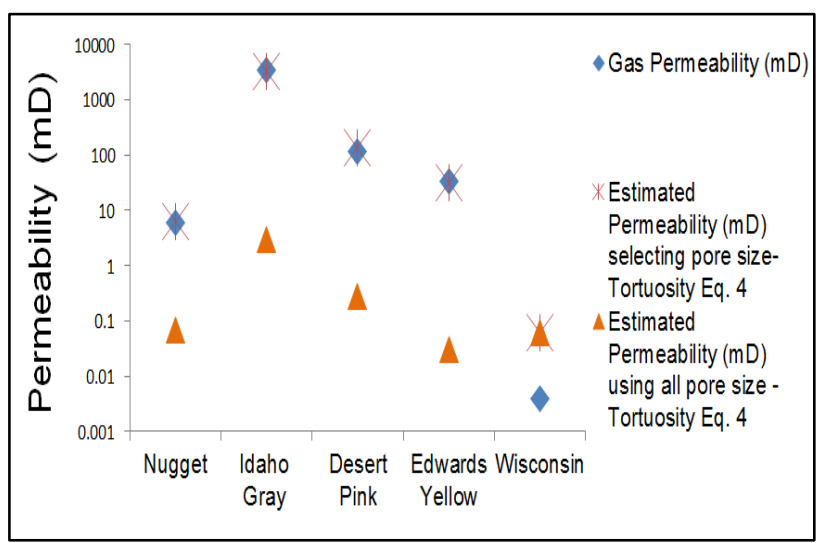

Figure 9 - Gas and estimated permeability. 
Acknowledgments (Font: Arial Bold, 9)

We thank UENF/LENEP, ANP-PRH-20, ANP-PRH-226 and PETROBRAS for financial support.

\section{References}

Attia, A. M., 2005. Effects ok petrophysical rock properties on tortuosity factor, Journal of petroleum Science and Engineering, Vol. 48: 185-198.

Azar, J.H., A. Javaherian., M. R., Pishvaie, and M. NabiBidhendi, 2008, An approach to defining tortuosity and cementation factor in carbonate reservoir rocks, Journal of Petroleum Science and Engineering, no. 2, Vol. 60: 125-131.

Carman, P., C, 1937, Fluid Flow through Granular Beds, Trans, Aiche, Vol. 15: 150-166.

Giesche, H., 2006, Mercury Porosimetry: a General (Practical) Overview, Particle \& particle systems characterization, Vol. 23: 9-19.

Glover, P., 2000, Petrophysics MSc Course Note, 198217.

Izadi,M., A. Ghalambor, 2013, New Approach in Permeability and Hydraulic Flow Unit Determination, SPE Reservoir Evaluation \& Engineering, Vol. 16: 257-264.

Latour, L.L., R. L., Kleinberg., P.P. Mitra., and C.H, Sotak 1995, Pore-size distributions and tortuosity in heterogeneous porous media, Journal of Magnetic Resonance, Series A, Vol. 112: 83-91.

León y León, C.A, 1998, New perspectives in mercury porosimetry, Advances in colloid and interface science, Vol. 76: 341-372.

Pittman, E.D., 1992, Relationship of porosity to permeability to various parameters derived from mercury injection-capillary pressure curves for sandstone: AAPG Bulletin, Vol. 76: 191-198.

Tiab, D., \& Donaldson, E. C. (2011). Petrophysics: theory and practice of measuring reservoir rock and fluid transport properties. Gulf professional publishing.

Webb, P., A, 2001, An introduction to the physical characterization of material by mercury intrusion porosimetry with emphasis on reduction and presentation of experimental data, Micromeritics Instrument Corp, Norcross, Georgia.

Worthington, A. E. (1975, January). Errors in the Laboratory Measurement of Formation Resistivity Factor. In SPWLA 16th Annual Logging
Symposium. Society of Petrophysicists and WellLog Analysts. 